\title{
THE TESTING OF EXPLOSIVES WITH REGARD TO THEIR ADMISSION FOR TRANSPORTATION.
}

I Y Y

GEH. REG. RAT PROF. DR. W. WILL.

['Translated from the Zeit. für das gesamte Schiess- und Sprengstoffwesen for August 15, I909. By W. J. Williams, F.I.C.].

For some time past there has been in progress a revision of the regulations governing the testing of explosives and powder in relation to their acceptance for transportation, to be incorporated in the new German Railroad Traffic Regulations. The Commission appointed to conduct the investigation and formulate a code of rules has arrived at a provisional conclusion and the results which are presented in the accompanying specifications have been embodied in section CIa of the Railroad Traffic Regulations.

In pursuing this investigation the endeavor was made to follow the plan indicated in the writer's communication on the subject to the Sixth International Congress in Rome and to make the conditions under which explosives may be safely transported dependent upon a series of investigations. Broadly considered, these consist of definite nethods of determining the properties which appear of importance as enclangering traffic.

Besides the chemical composition there should be determined the stability in storage, the behavior on ignition, the sensitiveness to mechanical influences the possibility of intermixture and other hazardous features. Further, there is to be taken into consideration to what extent the reciprocal influences of materials packed together or shipped together would be productive of danger.

According to the Railroad Traffic Regulations, explosives consist of those explosively dangerous substances which can only be provisionally accepted for forwarding. All substances capable of explosion are included, with the limitation that certain explosive substances, such as those which are not used for shooting and blasting, those which do not explode on ignition and those which are not more sensitive to shocks and blows than di- 
nitro-benzol are not considered explosives within the meaning of the regulations.

It appeared desirable to classify explosives under three fundamental groups, namely: (1) high cxplosives, (II) powders and (III) other substances capable of e.rplosion, and the two first again into sub-groups.

Group I.-The high explosives include:

I. Ammonium nitrate explosives.

2. Organic nitro-compounds.

3. Nitrated chlorhydrin.

4. Nitro-cellulose.

5. Chlorate and perchlorate explosives.

6. Black powder and similar explosives.

7. Dynamite and similar explosives.

\section{Group II.-The powders include:}

I. Smokeless colloided nitro-cellulose powder without nitroglycerin.

2. Smokeless colloided nitro-cellulose powder containing nitroglycerin.

3. Black powder.

According to the result of the investigation it was shown which explosives could be accepted in packages for transportation as explosives safe in handling in unlimited quantities. Classified under their respective groups these are:

Under Group I.--The so-called ammonium nitrate explosives, the not dangerous nitro-compounds, damp nitro-cellulose and certain explosives similar to black powder.

Under Group II.-Explosives which can only be carried in packages in quantities not exceeding 200 kilograms (440 lbs.) which include: the more insensitive chlorate and per-chlorate explosives; wet organic nitro-compounds which are more dangerous than picric acid; nitrated chlorhydrin.

Under Group III.-Explosives which can only be carried in special car loads, such as dynamite; the more dangerous black powders; gun-cotton and collodion-cotton; chlorate and perchlorate explosives.

Powders may be forwarded in packages in unlimited quantities, either as in Group I, including smokeless nitro-cellulose powders (also those containing nitroglycerin) which are well colloided and have certain definite conditions of stability, or as in Group II only in car-loads, which include those nitro-cellulose powders which do not attain these conditions of stability, black 
powder for shooting purposes (as a propellant) and similar powders.

If certain regulations as to packing are followed, these shooting powders of Group II can be forwarded in packages in quantities up to 200 kilograms ( $440 \mathrm{lbs}$.).

The admission of an explosive to railroad transportation, under any one of these groups, is governed by the results of the above mentioned tests, wherein it has shown itself to be as safe as those well known and comparable explosives tested simultaneously.

The methods of testing will be described later by my colleague, but it may be said in advance that such explosives as may be admitted to transportation in packages must have their respective composition and properties described as accurately as possible. For transportation in car-loads and with more stringent precautionary measures wider limits may be permitted in this respect.

This list at once becomes very large. This must, however, be tolerated until our experience in the mode of procedure is considerably increased. It may later be possible to simplify matters by including the single types in definite groups determined by numerous experimental researches.

It can be foreseen that an enlargement or the abolition of groups may be necessary, but such a preliminary attempt in the classification of explosives for transport based on systematic experimental tests may develop many errors, especially, as a comparatively short time was available for conducting the investigation. Despite this, the new ordinance appears an advance in safeguarding traffic and to be beneficial to the explosive industry in contrast to the regulations in force before their adoption.

The explosive manufacturer can now adapt his method of production to the prescribed requirements in keeping with the strictly defined tests and with the traffic regulations.

Further, it may be hoped that the prescribed tests will serve to prevent the appearance in commerce of such explosives as are prepared without adequate technical knowledge which are, on that account, dangerous in handling and in transit, and that the results based on extensive experimental work will prove of value in framing international traffic regulations. 